\title{
Induction of nitric oxide synthase and heme oxygenase activities by endotoxin in the rat adrenal cortex: involvement of both signaling systems in the modulation of ACTH-dependent steroid production
}

\author{
N Grion, E M Repetto, Y Pomeraniec, C Martinez Calejman, F Astort, R Sanchez, O P Pignataro ${ }^{1}$, P Arias ${ }^{2}$ \\ and C B Cymeryng \\ Departmento de Bioquímica Humana, Facultad de Medicina, Universidad de Buenos Aires, Paraguay $21555^{\circ}$, Buenos Aires C1121ABG, Argentina \\ ${ }^{1}$ IBYME-CONICET Buenos Aires, C1428ADN, Argentina. Departamento de Química Biológica, Facultad de Ciencas Exactas y Naturales, Buenos Aires \\ C1428EGA, Argentina \\ ${ }^{2}$ Departmento de Fistologia, Facultad de Medicina, Universidad de Buenos Aires, Paraguay $21555^{\circ}$, Buenos Aires C1121ABG, Argentina \\ (Requests for offprints should be addressed to C B Cymeryng; Email: cymeryng@fmed.uba.ar)
}

\begin{abstract}
The present study was designed to investigate the effect of lipopolysaccharide (LPS) on the expression levels and activities of the nitric oxide synthase (NOS) and heme oxygenase $(\mathrm{HO})$ systems in the rat adrenal gland. Both enzymatic activities were significantly increased in this tissue after in vivo treatment with LPS. The concurrent induction of the HO-1, NOS-1, and NOS-2 gene products was also detected as both mRNAs and protein levels were augmented by this treatment in a time-dependent way. A significant interaction between both signaling systems was also demonstrated as in vivo blockage of NOS activity with $\mathrm{N}(\mathrm{G})$-nitro-L-arginine methyl ester (L-NAME) resulted in a significant reduction in $\mathrm{HO}$ expression and activity levels,
\end{abstract}

while an increase in NOS activity was observed when $\mathrm{HO}$ was inhibited by Sn-protoporphyrin IX (Sn-PPIX). As both NOS and HO activities have been previously involved in the modulation of adrenal steroidogenesis, we investigated the participation of these signaling systems in the adrenal response to LPS. Our results showed that acute stimulation of steroid production by ACTH was significantly increased when either NOS or $\mathrm{HO}$ activities were inhibited. We conclude that adrenal NOS and $\mathrm{HO}$ can be induced by a non-lethal dose of endotoxin supporting a modulatory role for these activities in the adrenal response to immune challenges.

Journal of Endocrinology (2007) 194, 11-20

\section{Introduction}

Nitric oxide $(\mathrm{NO})$ and carbon monoxide $(\mathrm{CO})$ are involved in a wide array of biological processes (Moncada et al. 1991, Ryter et al. 2002). The biochemical pathways leading to NO formation from L-arginine have been associated with three NO synthase (NOS) isoforms differing in subcellular localization, regulation, and biological function (Palmer et al. 1988). Two constitutively expressed types first characterized in neurons and vascular endothelium are calcium- and calmodulin-dependent NOS (NOS-1 and NOS-3, respectively), whereas the inducible type (NOS-2) binds calmodulin tightly at normal intracellular $\mathrm{Ca}^{2+}$ concentrations. Its activity is thus generally considered to be $\mathrm{Ca}^{2+}$ independent and its expression is induced by a multiplicity of effectors like endotoxin, interferon (IFN)- $\gamma$, tumor necrosis factor- $\alpha$, hypoxia, stress, and tissue damage (Michel \& Feron 1997).

In mammals, microsomal heme oxygenase $(\mathrm{HO})$ is the rate-controlling enzyme for heme degradation. Its activity results in the production of $\mathrm{CO}$, free iron, and biliverdin. In the presence of NADPH-cytochrome P450 reductase and $\mathrm{NADPH}$, biliverdin is subsequently converted to bilirubin by biliverdin reductase (Tenhunen et al. 1969). To date three $\mathrm{HO}$ isoforms have been identified: the inducible enzyme HO-1, a second isoform, HO-2 that is constitutively active (Maines et al. 1986), and a third isozyme with low enzymatic activity (HO-3), which is predicted to play a role in either heme binding or sensing (McCoubrey et al. 1997). Immunolocalization techniques have shown basal expression of HO-2 in the brain, spleen, liver, testis, and vasculature (Maines 1997). HO-1, also known as the stress protein heat shock protein 32 (HSP32), is present in normal conditions in the spleen; however its augmented expression can be observed in various tissues following stressful stimuli, such as ultraviolet radiation, endotoxin, NO donors, heavy metals and hyperoxia/hypoxia, thus being associated with defense mechanisms against stressful situations (Immenschuh \& Ramadori 2000).

The HO and NOS families bear strong similarities. Both present constitutive and inducible isoforms. They share 
common stimulators, such as cytokines, endotoxin, and reactive oxygen species. In fact, regulatory mechanisms simultaneously controlling the activity of both $\mathrm{HO}-1$ and NOS-2 have been described (Choi \& Alam 1996, Maines 1997). However, important differences, such as chemical reactivity, stability and binding properties, suggest that both mediator systems are not redundant. In this sense, it has been proposed that these systems act coordinately and that any one might modulate the other's activity and/or expression levels (Takahashi et al. 1996, Foresti \& Motterlini 1999). It has been well established that $\mathrm{NO}$ donors can stimulate HO-1 gene expression and activity in a variety of cell types (Yee et al. 1996, Foresti et al. 1997), although the mechanisms underlying the modulation of $\mathrm{HO}-1$ by $\mathrm{NO}$ remain unclear. On the other side, it has been suggested that both inducible and constitutive HOs modulate the expression of NOS by depleting intracellular heme groups (Chakder et al. 1996, Turcanu et al. 1998). These findings suggest that in certain physiological or pathological situations there is a significant interaction between the $\mathrm{HO}$ and NOS systems. In these conditions, one enzymatic activity may counter regulate, compensate or prevail over the other.

Previous studies from our laboratory demonstrated the expression of both constitutive NOS isoforms and the induction of NOS-2 by lipopolysaccharide (LPS) in adrenal cells (Cymeryng et al. 2000, 2002). We have also presented evidence supporting a modulatory role for $\mathrm{NO}$ on adrenal steroidogenesis: NO donors (Cymeryng et al. 1998) and L-arginine (Cymeryng et al. 1999) significantly inhibit steroid synthesis by a mechanism that probably involves a direct interaction of $\mathrm{NO}$ with CYP11A1 (cytochrome P450scc). Based on these results we postulated NO to be an autocrine/ paracrine modulator of adrenal physiology (Cymeryng et al. 2002). As regards HO activity in the adrenal gland, recent studies from our laboratory indicate that, while HO-2 is constitutively expressed in adrenal cells, $\mathrm{HO}-1$ expression is induced by adrenocorticotrophin (ACTH). An inhibitory effect of HO activity on steroidogenesis could be inferred from our results (Pomeraniec et al. 2004).

Present in vivo experiments were designed to evaluate the interaction(s) between these gaseous signaling systems in the rat adrenal cortex. We first measured the impact of immune stimulation with LPS on NOS and HO expression and activity. Then, in a second series of experiments, we examined the effects of NOS or HO inhibitors (L-NAME or Sn-PPIX) on these enzymatic parameters, as well as on basal and ACTH-stimulated corticosterone release in animals pretreated with LPS or saline.

\section{Materials and Methods}

\section{Chemicals}

ACTH was obtained from ELEA Laboratories (Buenos Aires, Argentina). Anti-NOS antibodies were obtained from Santa
Cruz Biotechnology Inc. (Santa Cruz, CA, USA). AG 50W$\mathrm{X} 8$ cation exchange resin and peroxidase-conjugated antiIgG antibodies were purchased from Bio-Rad Laboratories Inc. Enhanced chemiluminescence (ECL) reagent came from Amersham Pharmacia Biotech. HO-1 and HO-2 antibodies were from StressGen Biotechnologies Corp. (Victoria, Canada).

LPS (Escherichia coli serotype O111:B4, lot 78H4086) and L-NAME were purchased from Sigma Chemical Co. Sn(IV)protoporphyrin IX dichloride was from Porphyrin Products Inc. (Logan, Utah, USA). All other reagents were commercial products of the highest grade available.

\section{Animals}

Adult male Wistar rats (Rattus norvegicus) weighting 200$250 \mathrm{~g}$ were used in the present study. The animals were kept in cages with controlled temperature $\left(23 \pm 2{ }^{\circ} \mathrm{C}\right)$ and lighting (12 h light:12 h darkness cycles) with free access to water and Purina chow. In order to minimize the effects of circadian fluctuation rats were killed in the morning. Animals were killed by decapitation according to protocols approved by the animal care and use committee from the University of Buenos Aires. Trunk blood was collected for corticosterone measurements, and adrenal tissues were excised immediately thereafter.

\section{Experimental procedures}

In the first set of experiments the rats were randomly assigned into control and treated groups, injected (i.p.) with either $200 \mu \mathrm{l}$ pyrogen-free saline alone or saline containing LPS $(500 \mu \mathrm{g} / \mathrm{kg}$ rat $)$ and killed after 3, 6, 12, and $18 \mathrm{~h}$.

In the second set of experiments the animals were randomly assigned to six groups that were injected (i.p.) with pyrogen-free saline alone or with LPS $(500 \mu \mathrm{g} / \mathrm{kg})$ or L-NAME $(50 \mathrm{mg} / \mathrm{kg})$ or SnPPIX $(20 \mathrm{mg} / \mathrm{kg})$ or LPS + L-NAME or LPS + SnPPIX. The rats were killed after $18 \mathrm{~h}$. In addition, in a third set of experiments selected groups of animals were treated with ACTH $(7.5 \mathrm{IU} / \mathrm{kg}$, i.p.) $60 \mathrm{~min}$ before killing.

Corticosterone was extracted from serum with dichloromethane and its levels were assessed by radioimmunoassay. Corticosterone antisera were kindly provided by Dr A Bélanger, Laval University, Quebec, Canada.

\section{Zona fasciculata-reticularis $(Z F-R)$ tissue preparation}

Adrenal glands were rapidly dissected and placed on a chilled plate. The surrounding fat was removed and the glands were halved. The capsule together with the adhering zona glomerulosa cells was carefully dissected away. Finally, the medulla was excised under a dissecting microscope.

ZF-R adrenal tissue was homogenized in $50 \mathrm{mM} \mathrm{KPO}_{4}$ $\mathrm{pH} 7 \cdot 4,0 \cdot 2 \mathrm{mM}$ EDTA, $0 \cdot 25 \mathrm{M}$ sucrose, $10 \mu \mathrm{M}$ pepstatin, $10 \mu \mathrm{M}$ leupeptin, and $0 \cdot 8 \mu \mathrm{M}$ aprotinin in a final volume of 
$0.2 \mathrm{ml}$ per gland. The homogenate was first centrifuged at $2000 \mathrm{~g}$ for $10 \mathrm{~min}$, then at $9000 \mathrm{~g}$ for $20 \mathrm{~min}$ and finally at $105000 \mathrm{~g}$ for $60 \mathrm{~min}$ to obtain cytosolic and microsomal fractions. In some experiments a portion of ZF-R adrenal gland tissue was homogenized in TRIzol reagent in order to obtain RNA.

\section{$R N A$ isolation and RT-PCR}

Total RNA was obtained from ZF-R adrenal tissue with Trizol reagent according to the manufacturer's instructions. RNA $(2 \mu \mathrm{g})$ was pretreated with RNAse-free DNAse, heated at $70{ }^{\circ} \mathrm{C}$ for $10 \mathrm{~min}$, placed on ice for $1 \mathrm{~min}$ and then incubated with a mixture containing $0.5 \mathrm{mM}$ dNTPs mix, $25 \mathrm{ng} / \mu \mathrm{l}(8 \mu \mathrm{M})$ random primers, $1 \times$ first strand buffer, 25 units rRNAse inhibitor, 200 units Moloney murine leukemia virus (MMLV) reverse transcriptase, and water to a final volume of $25 \mu \mathrm{l}$ for $1 \mathrm{~h}$ at $42{ }^{\circ} \mathrm{C}$. The reaction was stopped by heating at $90^{\circ} \mathrm{C}$ for $5 \mathrm{~min}$. The reaction mixture was brought to $100 \mu \mathrm{l}$ with diethylpyrocarbonate-treated water and stored at $-70{ }^{\circ} \mathrm{C}$. In selected tubes the reverse transcriptase was omitted as a control of amplification from contaminating genomic DNA.

PCRs were carried out in a Tpersonal Thermocycler (Biometra Biomedizinische Analytik, Göttingen, Germany) and were performed using $2 \mu \mathrm{l}$ cDNA for the amplification of specific gene products. The PCR was performed in a final volume of $20 \mu \mathrm{l}$ of the following reaction mixture: $1 \times \mathrm{PCR}$ buffer, $1.5 \mathrm{mM} \mathrm{MgCl}_{2}, 0 \cdot 2 \mathrm{mM}$ of each dNTP, $500 \mathrm{nM}$ of each specific oligonucleotide primer, and $0.625 \mathrm{U}$ Taq polymerase (Life Technologies). The sequence for the oligonucleotide primers were as follows: for HO-1: forward: $5^{\prime}$-ACTTTCAGAAGGGTCAGGTGTCC-3' reverse: 5'-TTGAGCAGGAAGGCGGTCTTAG-3' (522 bp fragment); for HO-2: forward primer $5^{\prime}$ - CCACCACTGCACTTTACTTC-3'; reverse primers $5^{\prime}$-GGTCTTCATACTCAGGTCCA- $3^{\prime}$ (436 bp fragment), for NOS1: forward: $5^{\prime}$-TTTCTGTCCGTCTCTTCAAACGCAAAGTGG-3', reverse: $5^{\prime}-$ GCGGGAGACTGTTCGTTCTCTGAATACGGG-3' ${ }^{\prime}$, for NOS2: forward: $5^{\prime}$ - CACGGAGAACAGCAGAGTTGG-3', reverse: 5'-GGAACACAGTAATGGCCGACC-3'. For NOS3: forward: 5'-CTGTGTCCAACATGCTGCTAGAAATTG-3', reverse: $5^{\prime}$-TAAAGGTCTTCTTCCTGGTGATGCC-3'. GAPDH; forward primer: 5'-TCCCTCAAGATTGTCAGCAA-3', reverse primer: $5^{\prime}$-AGATCCACAACGGATACATT-3' (309 bp fragment). The identity of the amplified products was confirmed by direct sequencing.

\section{Immunoblot analysis}

Samples were boiled for $5 \mathrm{~min}$ in SDS-PAGE loading buffer and electrophoresed on $7 \cdot 5 \%$ or $12 \%$ polyacrylamide gels. After electrophoresis, proteins were transferred to polyvinylidene difluoride (PVDF) membranes for $1 \mathrm{~h}$ at $15 \mathrm{~V}$ in a Trans-Blot SD system (Bio-Rad Laboratories Inc.) in $48 \mathrm{mM}$ Tris- $\mathrm{HCl} \mathrm{pH} 9 \cdot 2,39 \mathrm{mM}$ glycine and $1.3 \mathrm{mM}$ SDS. PVDF

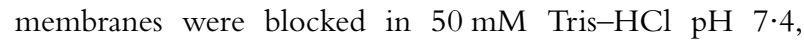
$0 \cdot 15 \mathrm{M} \mathrm{NaCl}, 0 \cdot 25 \%$ Tween 20 and $5 \%$ non-fat milk for $60 \mathrm{~min}$ at room temperature and then incubated overnight with a 1:500 dilution of the respective NOS (Santa Cruz Biotechnology Inc.), HO (StressGen Biotechnologies Corp.) or $\gamma$-tubuline (Sigma-Aldrich) antiserum at $4{ }^{\circ} \mathrm{C}$. Membranes were washed with $50 \mathrm{mM}$ Tris $-\mathrm{HCl} \mathrm{pH} 7 \cdot 4$, $0 \cdot 15 \mathrm{M} \mathrm{NaCl}$, and $0 \cdot 25 \%$ Tween 20 and then incubated for $2 \mathrm{~h}$ with a 1:5000 dilution of a goat anti-rabbit IgG antibodyhorseradish peroxidase conjugate. The filters were washed, and the bands were visualized by chemiluminescence (ECL Western Blotting Analysis System, Amersham Pharmacia Biotech) and autoradiography.

\section{NOS activity}

NOS activity was determined in cytosolic fractions from rat adrenal ZF-R by monitoring the conversion of L- $\left[{ }^{3} \mathrm{H}\right]$ arginine into $\mathrm{L}-\left[{ }^{3} \mathrm{H}\right]$ citrulline as previously described (Cymeryng et al. 2002). Fifty micro liter protein fractions were incubated with $50 \mu \mathrm{l}$ reaction buffer $(20 \mathrm{mM}$ HEPES, $20 \mu \mathrm{M}$ L-arginine, $1 \mathrm{mM}$ dithiotreitol, $1 \mathrm{mM} \mathrm{NADPH}$, $187 \mathrm{nM} \mathrm{L}-\left[2,3-{ }^{3} \mathrm{H}\right]$ arginine, and $\left.2 \cdot 4 \mathrm{mM} \mathrm{CaCl} 2\right)$ at $37^{\circ} \mathrm{C}$ for $15 \mathrm{~min}$. The reaction was terminated by the addition of $800 \mu \mathrm{l}$ ice cold suspension of the cation exchange resin AG $50 \mathrm{~W}-\mathrm{X} 8$ in stop buffer $(10 \mathrm{mM}$ EGTA, $10 \mathrm{mM}$ EDTA, and $50 \mathrm{mM}$ HEPES, pH 5). L- $\left[{ }^{3} \mathrm{H}\right]$ citrulline was quantified in the supernatants by liquid scintillation spectroscopy. NOS activity is shown as picomoles of $\mathrm{L}-\left[{ }^{3} \mathrm{H}\right]$ citrulline formed/mg protein per minute.

\section{HO activity}

HO activity was determined in the microsomal fractions by monitoring the conversion of heme into bilirubin as previously described (Pomeraniec et al. 2004). In brief, $50 \mu \mathrm{l}$ microsomal proteins were incubated with $100 \mu \mathrm{l}$ reaction mixture containing $0.33 \mathrm{mM}$ hemin, $0.5 \mathrm{mg} / \mathrm{ml}$ rat liver cytosol, $0 \cdot 2 \mathrm{mM} \mathrm{MgCl}, 2 \mathrm{mM}$ glucose 6 phosphate, 1.62 units $/ \mathrm{ml}$ glucose 6 phosphate dehydrogenase, $0.5 \mathrm{mM}$ $\mathrm{NADPH}$, and $25 \mathrm{mM}$ potassium phosphate buffer $(\mathrm{pH} 7 \cdot 4)$ at $37^{\circ} \mathrm{C}$ for $2 \mathrm{~h}$. The reaction mixture was then extracted with $0.6 \mathrm{ml}$ chloroform and the bilirubin concentration of the chloroform layer was spectrophotometrically measured by the difference in absorbance between 464 and $530 \mathrm{~nm}$ $(\xi=40 \mathrm{mM} / \mathrm{cm})$. HO enzyme activity is indicated as nmoles of bilirubin formed/mg protein per hour.

\section{Statistical analysis}

All values are expressed as mean \pm S.E.M. of $n$ experiments. Differences between groups were analyzed by factorial oneway ANOVA. When the ANOVA was significant $(P<0 \cdot 05)$ post hoc comparisons (Dunnet's or Tuckey's test) were made to determine the statistical levels of difference between groups 
using GraphPad InStat version 3.06 for Windows (GraphPad Software, San Diego, CA, USA).

\section{Results}

We first examined the effect of LPS on HO activity and expression levels in the rat adrenal cortex at different time points. As depicted in Fig. 1A, HO-1 mRNA levels were elevated 3 and $6 \mathrm{~h}$ post-treatment throughout the duration of the experiment. No changes were detected in $\mathrm{HO}-2 \mathrm{mRNA}$ levels after LPS challenge. Accordingly, western blot analysis also showed an LPS-dependent increase in HO-1 levels $6 \mathrm{~h}$ after injection that was still evident at $18 \mathrm{~h}$. In contrast, the expression of HO-2 did not change at the different time points examined (Fig. 1B). HO activity was significantly increased 12 and $18 \mathrm{~h}$ after the immune challenge (Fig. 1C).

The temporal pattern of NOS activity and expression was also analyzed in this model. As shown in Fig. 2A, no NOS-2 mRNA was detected by RT-PCR analysis in the adrenal cortex of untreated animals, while a strong signal was observed at 3 and $6 \mathrm{~h}$ post-LPS injection, disappearing thereafter. NOS-1 and NOS-3 transcripts were also increased $6 \mathrm{~h}$ post-injection. As expected, LPS treatment caused a marked rise in NOS-2 and NOS-1 protein levels, while NOS-3 protein levels were not affected. NOS activity was significantly elevated $6 \mathrm{~h}$ after LPS injection and remained elevated up to $18 \mathrm{~h}$ (Fig. 2C).

In order to investigate the interaction between both gaseous signaling systems in the adrenal cortex of the rat, the effects of in vivo treatment with the inhibitors for NOS and HO (L-NAME and Sn-PPIX) were studied both in control and LPS-treated animals. Determinations were performed $18 \mathrm{~h}$ after injection of LPS, a time point at which the activity of both enzymes was significantly elevated. As illustrated in Fig. 3, in vivo inhibition of NOS activity with L-NAME inhibited the increase in HO-1 mRNA levels produced by LPS (Fig. 3A), while it had no effect on the levels of the HO-2 transcript. L-NAME treatment partially blocked

A

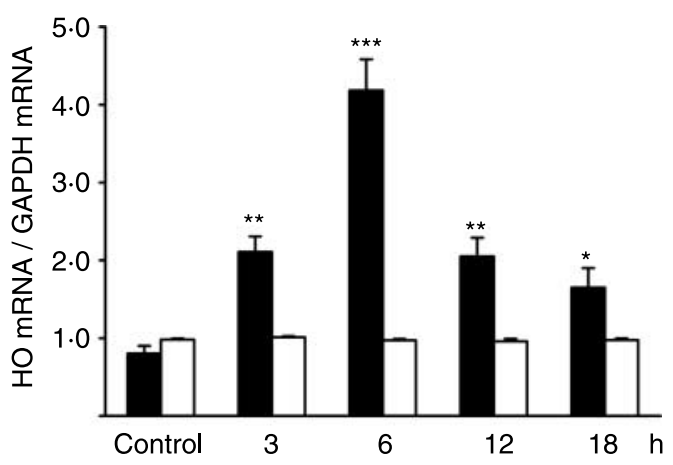

B

C
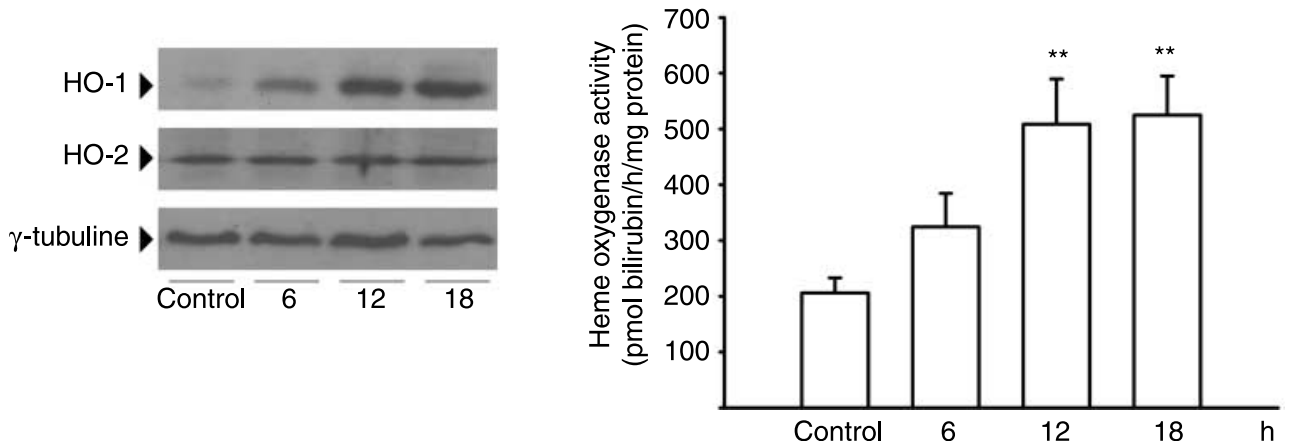

Figure 1 Effect of LPS on $\mathrm{HO}$ activity and expression in rat adrenal ZF-R. Animals were injected with saline alone or with LPS (i.p., $500 \mu \mathrm{g} / \mathrm{kg}$ ) and killed 3, 6, 12 and $18 \mathrm{~h}$ after. Adrenal glands were rapidly excised and homogenized as described under Materials and Methods and $\mathrm{HO}$ expression levels and activity were determined. (A) RT-PCR products of HO-1 and HO-2. Semiquantitative analysis was performed on equal amounts of total RNA ( $2 \mu \mathrm{g})$ with specific primers pairs. The histogram shows the densitometric analysis of the relative abundance of HO-1 (solid bar) and HO-2 (open bar) mRNAs normalized with the corresponding GAPDH. Each bar represents means \pm s.E.M. $(n=3) ;{ }^{* * *} P<0 \cdot 001 ;{ }^{* *} P<0 \cdot 01$, and ${ }^{*} P<0 \cdot 05$ versus control by Tuckey's test. (B) Western blot analysis for HO-1, HO-2 and $\gamma$-tubuline proteins obtained from the same experiment as in (A). (C) $\mathrm{HO}$ activity was determined spectrophotometrically as described before. Each point represents means \pm S.E.M. of three experiments performed independently, $* * P<0 \cdot 01$ versus control by Dunnett's test. 
A
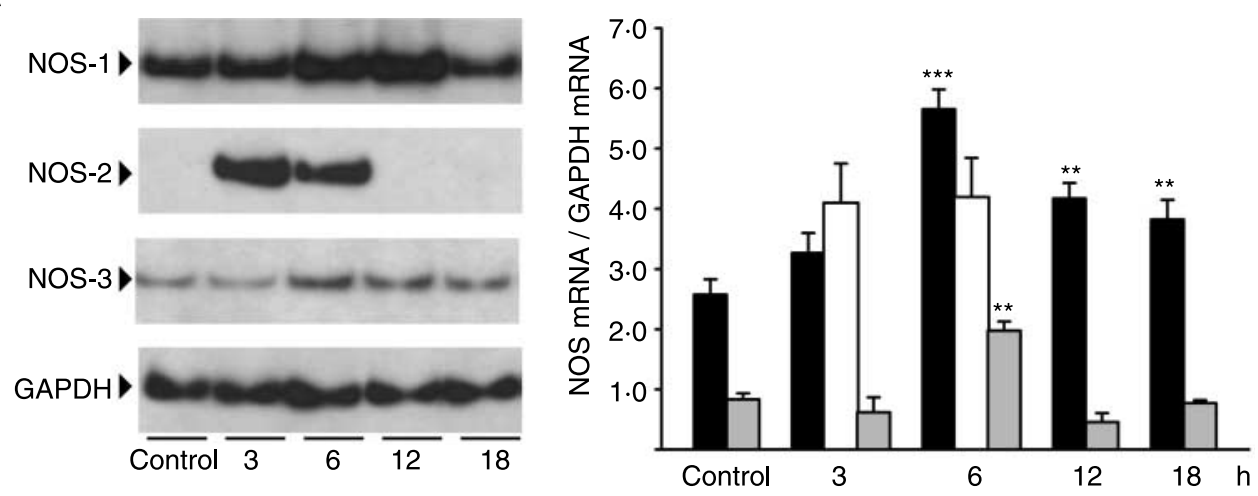

B
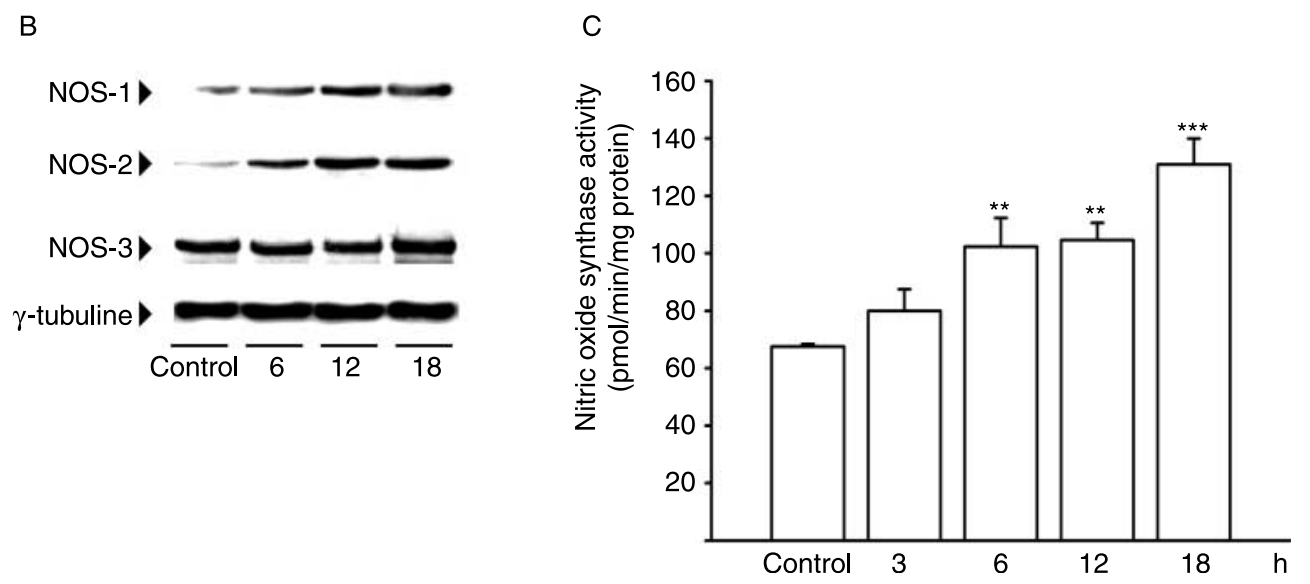

Figure 2 Effect of LPS on NOS activity and expression in rat adrenal ZF-R. Animals were treated as described in the legend of Fig. 1. NOS activity and expression levels were determined at different time points after LPS treatment. (A) Semiquantitative RT-PCR analysis of NOS-1, NOS-2 and NOS-3 expression levels. PCRs were performed as described in Materials and Methods with the inclusion of tracer quantities of $\left[\alpha_{-}^{-32} \mathrm{P}\right] \mathrm{dCTP}$ in the reaction mixture and PCR products were then separated by SDS-PAGE. The densitometric analysis shows the relative abundance of gene transcripts compared with the housekeeping gene GAPDH. Each bar, NOS-1 (solid bar), NOS-2 (open bar) and NOS-3 (grey bar) represents means \pm S.E.M., $n=3$. ${ }^{* * *} P<0 \cdot 001$ and ${ }^{* *} P<$ $0 \cdot 01$ versus respect control by Tukey's test. (B) Western blot analysis of NOS-1, NOS-2, NOS-3 and $\gamma$-tubuline proteins obtained in the same experiment as in A). (C) NOS activity was determined by the radiochemical Conversion of $L-\left[{ }^{3} \mathrm{H}\right]$ arginine to $L-\left[{ }^{3} \mathrm{H}\right]$ citrulline. Each point represents the means \pm S.E.M. of four experiments performed independently, $* * P<0 \cdot 01,{ }^{* * *} P<0 \cdot 001$ versus control by Dunnett's test.

the stimulation of HO activity induced by LPS (Fig. 3B, left panel). Figure 3B (right panel) also shows the marked inhibition of NOS activity attained after L-NAME treatment in both control and LPS-injected animals.

Similar experiments were performed in order to assess the effect of $\mathrm{HO}$ inhibition on the NO generator system, animals being injected with saline, LPS, Sn-PPIX or LPS + Sn-PPIX. NOS-1 mRNA levels were significantly increased in LPS + Sn-PPIX-treated rats, while NOS-3 mRNA levels were increased by Sn-PPIX and LPS + SN-PPIX (Fig. 4A). NOS2 mRNA levels were undetectable $18 \mathrm{~h}$ after LPS + SnPPIX treatment (data not shown). NOS activity was significantly increased by Sn-PPIX treatment, both in control and LPSstimulated animals (Fig. 4B, left panel). HO activity in these experimental conditions is shown as a control (Fig. 4B, right panel).
Blood corticosterone levels were significantly elevated after LPS treatment, remaining above control levels throughout the sampling period (Fig. 5A). ACTH-stimulated corticosterone secretion was evaluated $18 \mathrm{~h}$ after treatment initiation in saline or in LPS - , LPS + L-NAME-, or LPS + Sn-PPIX-injected animals. Systemic inhibition of either NOS or HO activities induced a significant increase in ACTH-related corticosterone release (Fig. 5B).

\section{Discussion}

The results presented here demonstrate that in vivo treatment with LPS increases both NOS and $\mathrm{HO}$ activities in the rat adrenal cortex. In addition, a significant interaction between 
A

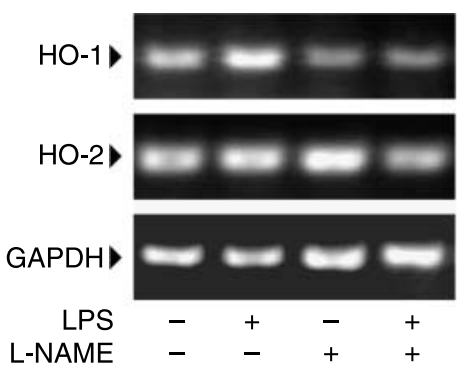

B

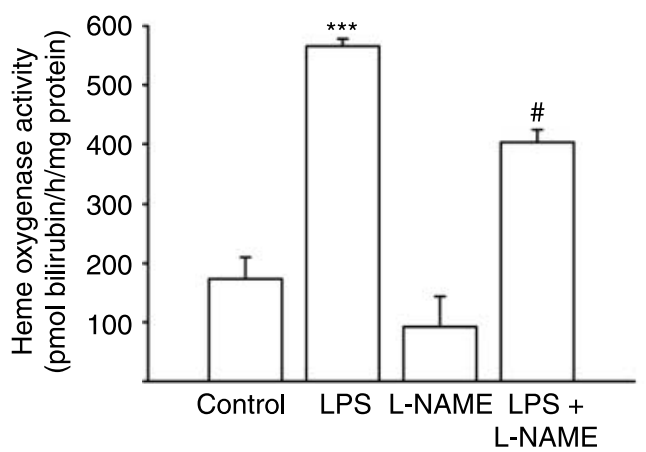

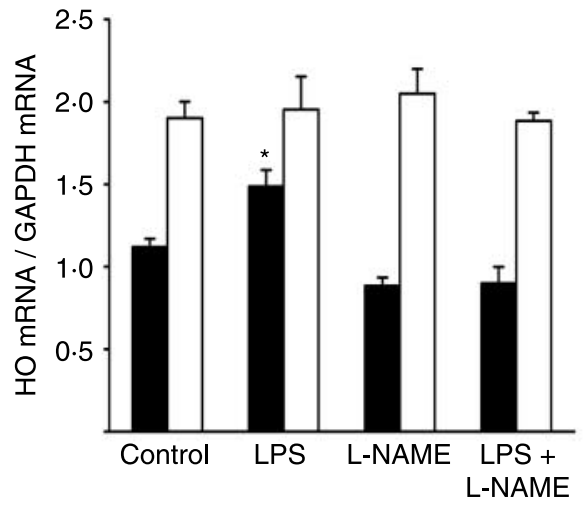

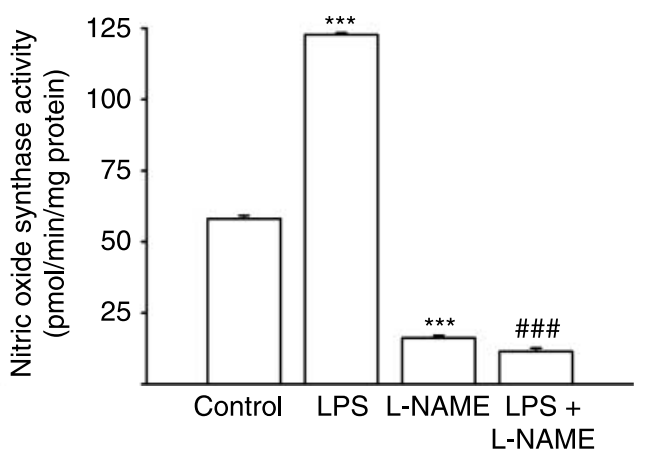

Figure 3 Effect of L-NAME on $\mathrm{HO}$ activity and expression levels induced by LPS, in rat adrenal cortex. Rats injected with saline alone or with LPS $(500 \mu \mathrm{g} / \mathrm{kg})$ or L-NAME $(50 \mathrm{mg} / \mathrm{kg})$ or LPS + L-NAME were killed $18 \mathrm{~h}$ after injection. (A) Semiquantitative RT-PCR products of $\mathrm{HO}$ isoforms. Relative abundance of HO-1 and HO-2 mRNAs is compared with GAPDH. Each bar, HO-1 (solid bar) and HO-2 (open bar), represents means \pm S.E.M., $n=3, * P<0 \cdot 01$ versus its respective control, by Tukey's test. (B) Enzymatic activities of $\mathrm{HO}$ (left panel) and NOS (right panel) are shown. Data represents means \pm S.E.M., $n=4,{ }^{* * *} P<$ $0 \cdot 001$ versus control; ${ }^{\# \#} P<0 \cdot 001$ and ${ }^{\#} P<0 \cdot 01$ versus LPS alone by Tukey's test.

both signaling systems and its influence on ACTH-dependent steroid production is described.

An involvement of $\mathrm{HO}$ activity in the LPS-dependent modulation of AVP, CRH, and ACTH release has been suggested (Kostoglou-Athanassiou et al. 1998, Mancuso et al. 1999). Since LPS treatment did not modify the expression levels of any of the HO isozymes at hypothalamic or pituitary level (Jacobs et al. 1997, Satta et al. 1998) these effects could be due to changes in enzymatic activity. In previous experiments from our laboratory, $\mathrm{HO}$ activity (mainly attributed to the expression of $\mathrm{HO}-2$ ) has been detected in basal conditions and ACTH-dependent HO-1 induction was also demonstrated in adrenal cells (Pomeraniec et al. 2004). To our knowledge, the results presented in this paper are the first report on the LPS-dependent induction of HO-1 along the hypothalamus-hypophyseal-adrenal (HHA) axis.

The stimulatory effect of inflammatory stress caused by LPS on $\mathrm{HO}$ activity has been widely documented, both in vitro and in vivo. Comparable results were obtained in mice liver (Rizzardini et al. 1993), rat Kuppfer cells (Immenschuh et al.
1999), macrophages (Srisook \& Cha 2004), and rat glial cells (Kitamura et al. 1998). As was also demonstrated in other tissues or cell types, the induction of this enzymatic activity is probably involved in the development of cytoprotective mechanisms triggered by both injury and infection (Ryter \& Tyrrell 2000). In this sense, we have previously demonstrated that the ACTHdependent increase in $\mathrm{HO}$ activity observed in adrenal cells correlated with diminished levels of TBARs and proteincarbonyls, both parameters of oxidative stress (Pomeraniec et al. 2004). This effect is probably associated with a decrease in the pro-oxidant levels of heme or alternatively, to the endogenous antioxidant activity of bilirubin, as demonstrated in Y1 cells (Pomeraniec et al. 2004).

LPS treatment has been described to increase levels of both NOS-1 and NOS-2 mRNAs (Harada et al. 1999) in the hypothalamus, and of NOS-2 mRNA at the pituitary level (Satta et al. 1998). However, the relevance of NO signaling to LPS-induced ACTH secretion is still controversial (Harada et al. 1999). 
A

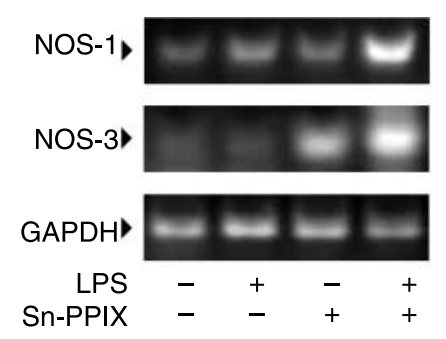

B

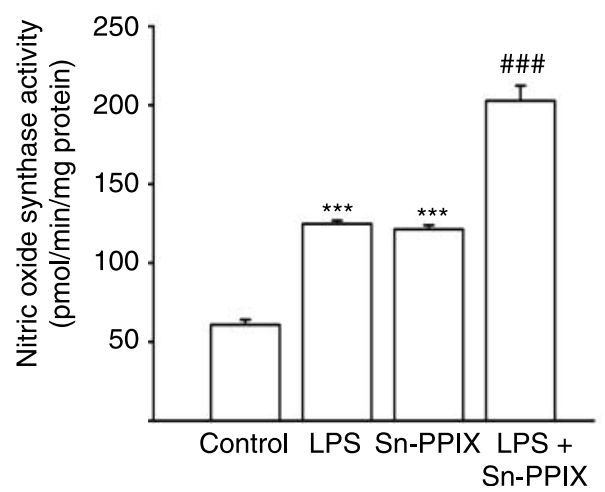

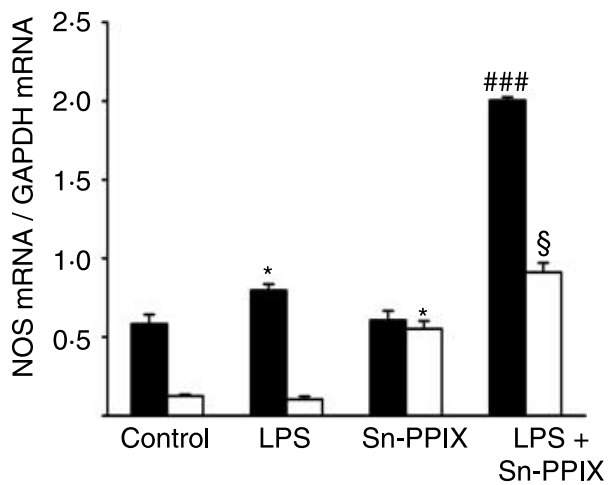

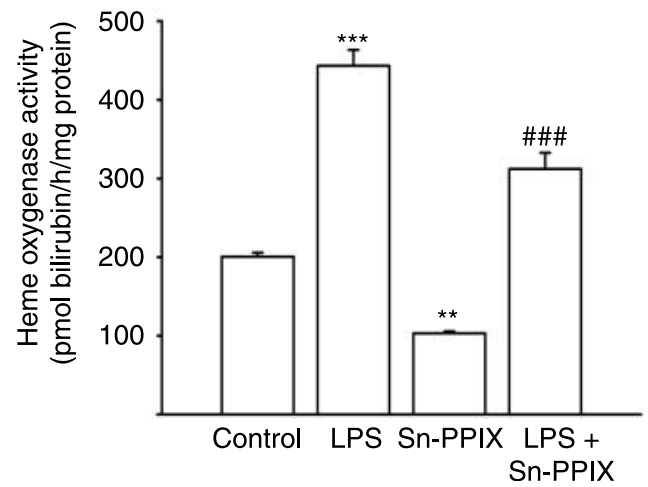

Figure 4 Effect of Sn-PPIX on NOS activity and expression levels induced by LPS in rat adrenal cortex. Rats were injected with saline alone or in combination with LPS $(500 \mu \mathrm{g} / \mathrm{kg})$, or Sn-PPIX $(20 \mathrm{mg} / \mathrm{kg})$ or with LPS + Sn-PPIX and killed $18 \mathrm{~h}$ after. (A) Semiquantitative RT-PCR of NOS-1 and NOS-3 products. The densitometric analysis shows the relative abundance of gene transcripts compared with the housekeeping gene GAPDH. Data expressed as means \pm S.E.M., $n=3$, corresponds to NOS-1 (solid bar) and NOS-3 (open bar) transcripts. $* P<0.05$ versus control, ${ }^{\# \#} P<0.001$ and ${ }^{\S} P<0.05$ versus Sn-PPIX alone, by Tukey's test. (B) Enzymatic activities of NOS (left panel) and HO (right panel) are shown. Each point represents means \pm s.E.M. of four experiments performed independently, ${ }^{* *} P<0 \cdot 01$ and ${ }^{* * *} P<0 \cdot 001$ versus control; ${ }^{\# \#} P<0 \cdot 001$ versus Sn-PPIX alone by Tukey's test.

In the rat adrenal cortex both constitutive NOS isozymes were detected in basal conditions (Cymeryng et al. 2002). Present results show that LPS treatment significantly increased NOS activity and markedly induced the expression of NOS-1 and NOS-2 isozymes in this tissue.

Production of NO by NOS-2 is an evolutionarily conserved mechanism of host defense. Nitrosative and oxidative stress cause the death of exogenous agents but could also result in deleterious effects to host cells. In order to prevent these effects a plethora of antioxidant mechanisms came into place. Among them, induction of HO-1 by several stressful stimuli (u.v. radiation, endotoxin, NO donors, heavy metals, hyperoxia and hypoxia) has been demonstrated (Ryter \& Tyrrell 2000).

As in the rat adrenal cortex, both NOS and HO enzymatic activities were increased by LPS treatment, we explored possible interactions among these signaling pathways. Many reports have previously indicated that $\mathrm{NO}$ donors increase $\mathrm{HO}$ activity and induce the expression of HO-1 in different cell types (Otterbein \& Choi 2000). In this sense, (Immenschuh et al. 1999) have shown that HO-1 induction by LPS is mediated by NO. The attenuation of $\mathrm{HO}$ activity by NOS inhibitors has also been demonstrated both in vitro and in vivo models (Datta \& Lianos 1999, Datta et al. 2002). In our experiments, the increase in $\mathrm{HO}$ activity was preceded by the activation of the nitridergic system, and the blockade of this system by L-NAME significantly inhibited the LPS-dependent increase in $\mathrm{HO}$ activity. L-NAME treatment also blunted the LPS-associated increase in HO-1 mRNA levels. According to these results it could be speculated that an increase in NO generation is involved in LPS-dependent stimulation of $\mathrm{HO}$ activity.

Analysis of the effect of $\mathrm{HO}$ activity on the nitridergic system showed that blockage with Sn-PPIX further 

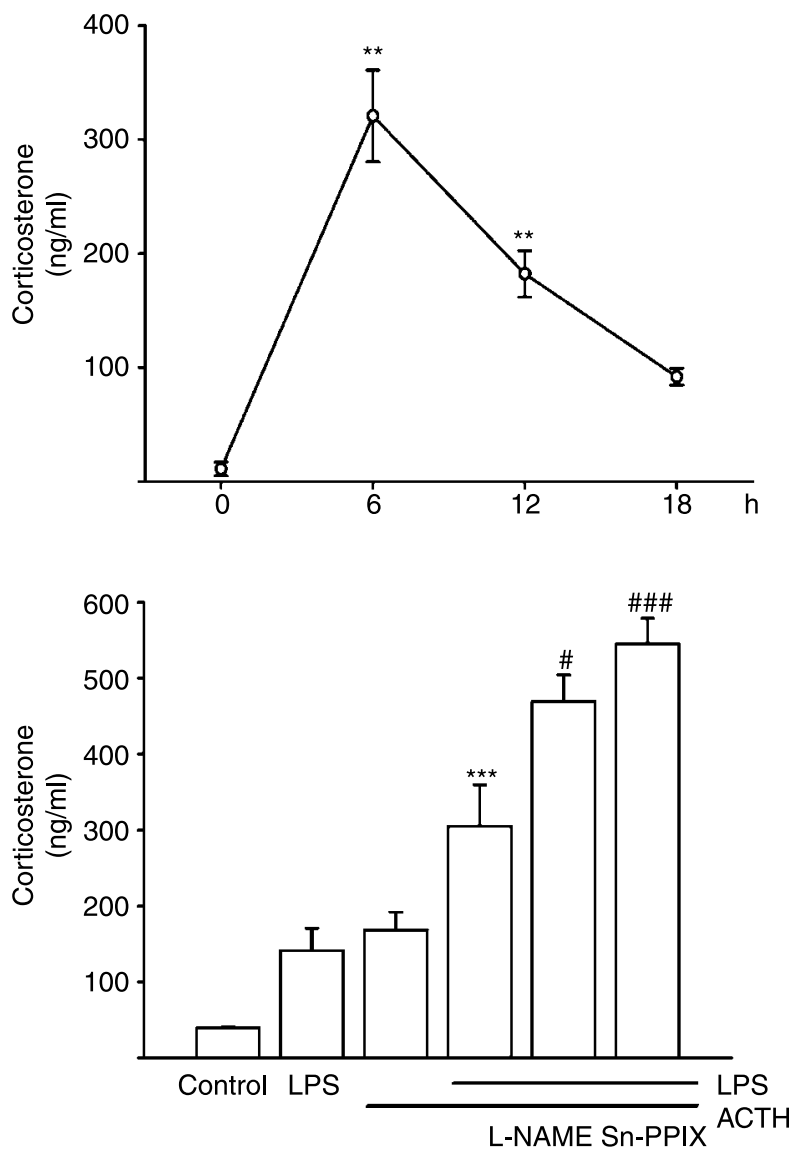

Figure 5 Corticosterone production in LPS-treated animals. (A) Time course of serum corticosterone levels after i.p. injection of LPS $(500 \mu \mathrm{g} / \mathrm{kg})$. Data are means \pm s.E.M. for three independent experiments. ${ }^{* * P}<0 \cdot 01$ versus control by Dunnett's test. (B) Effect of NOS or $\mathrm{HO}$ inhibition on serum corticosterone levels acutely induced by ACTH on LPS treated rats. Rats were i.p. injected with saline or LPS $(500 \mu \mathrm{g} / \mathrm{kg})$ alone or in combination with L-NAME $(50 \mathrm{mg} / \mathrm{kg})$ or with Sn-PPIX (20 mg/kg) $18 \mathrm{~h}$ before ACTH stimulation $(7.5 \mathrm{IU} / \mathrm{kg}$, i.p.). Corticosterone levels were determined one hour later. Data are expressed as means \pm S.E.M., $n=3, * * * P<0 \cdot 001$ versus control, ${ }^{\#} P<0 \cdot 05$ and ${ }^{\# \#} P<0.001$ versus LPS + ACTH by Tukey's test.

augmented LPS-induced NOS activity. These results could be explained by the following hypothesis: (1) as heme is involved in the catalytic activity of NOS, this enzyme is susceptible to inhibition by CO (White \& Marletta 1992); (2) HO activity could also regulate NO generation as NOS could provide heme as a substrate for $\mathrm{HO}$; and (3) $\mathrm{HO}$ products could inhibit gene transcription, as was demonstrated for bilirubin (Wang et al. 2004).

Previous results from our laboratory demonstrate that both NOS and HO activities are involved in the modulation of adrenal steroidogenesis (Cymeryng et al. 1998, 1999, Pomeraniec et al. 2004). As shown previously in rats, systemic administration of LPS elicits a prompt release of ACTH and corticosterone: peak values were attained around 1 or $2 \mathrm{~h}$ after injection, and basal levels were regained 3-4 h post-injection
(Uribe et al. 1999, Ma et al. 2000). In our experimental setting LPS also induced a rapid increase in serum corticosterone levels but a significant effect of LPS on NOS and HO activities was evident only $6 \mathrm{~h}$ after treatment. It is thus suggested that these activities might be involved in later stages of the adrenal response to LPS. In fact, $18 \mathrm{~h}$ after LPS injection both $\mathrm{HO}$ and NOS activities appear to negatively modulate the adrenal response to exogenous ACTH as corticosterone levels were significantly increased when either of these activities was blocked. This effect might be attributed to the interaction of $\mathrm{NO}$ or $\mathrm{CO}$ with the heme moiety of cytochrome p450 enzymes, as was previously described (Morgan et al. 2001).

The endotoxic activity of LPS appears to be mediated by the interaction with specific cell surface receptor(s). In this sense, the expression of Toll-like receptors 4 and 2 in human adrenal cells (Bornstein et al. 2004) and a direct effect of LPS on corticosterone production in rat fasciculata-reticularis cells have been demonstrated (Enriquez de Salamanca \& Garcia 2005). According to these results the observed effects of LPS on the adrenal cortex could be attributed to LPS alone, or to a combination of LPS with enhanced cytokine production and/or ACTH release resulting from LPS injection as was also suggested (Beishuizen \& Thijs 2003). The exact nature of the adrenal stimulant remains to be established.

Steroid-producing cells within the adrenal cortex constitutively express NOS-1, NOS-3, and HO-2 enzymes, and respond to an immune challenge by increasing NOS-2 expression and activity (Cymeryng et al. 2000, 2002, Pomeraniec et al. 2004). As discussed in previous reports from our laboratory (Cymeryng et al. 2002), the obtained ZF-R fragments necessarily contain different proportions of endothelial, neuronal, and immune cells displaying NOS and/or HO activity. The contribution of these inevitable 'contaminants' to the observed changes in enzyme messenger/protein/activity cannot be ascertained in the present experiments and is beyond the scope of this study. However, the in vivo approach employed in this study allows a comprehensive evaluation of the steroidogenic response to LPS and its possible regulation by gaseous messenger systems.

The adrenal gland is involved in the complex set of reactions evoked by tissue trauma, chemical irritants, or infection. Corticosteroids produced in the zona fasciculata act as a major feedback control limiting inflammatory responses and preventing the immune system from over-reacting and causing tissue damage or autoimmunity, and in this sense they are essential for survival in critical illness. Furthermore, glucocorticoids are also involved in numerous aspects of metabolism, growth and physiological functioning (Beishuizen \& Thijs 2003). All the above considered, the existence of modulatory mechanisms controlling glucocorticoid production, such as the NOS and HO systems, acquires the utmost importance, as they enable the gland to provide a finely tuned response that is essential in illness and other stressful situations. 
In conclusion, the results presented above demonstrate the induction of both NOS and HO systems in the adrenal gland and the participation of both signaling systems in the modulation of ACTH-dependent steroid production in the context of an immune response. A significant interaction between both enzymatic systems is also shown. It is suggested that NO derived from LPS-induced NOS entails an increase in $\mathrm{HO}$ activity and that this activity, in turn, is involved in the consequent inhibition of NOS.

\section{Acknowledgements}

This work was supported by grants from Universidad de Buenos Aires and CONICET. The authors declare that there is no conflict of interest that would prejudice the impartiality of this scientific work.

\section{References}

Beishuizen A \& Thijs LG 2003 Endotoxin and the hypothalamo-pituitaryadrenal (HPA) axis. Journal of Endotoxin Research 9 3-24.

Bornstein SR, Schumann RR, Rettori V, McCann SM \& Zacharowski K 2004 Toll-like receptor 2 and Toll-like receptor 4 expression in human adrenals. Hormone and Metabolic Research 36 470-473.

Chakder S, Rathi S, Ma XL \& Rattan S 1996 Heme oxygenase inhibitor zinc protoporphyrin IX causes an activation of nitric oxide synthase in the rabbit internal anal sphincter. Journal of Pharmacology and Experimental Therapeutics 277 1376-1382.

Choi AM \& Alam J 1996 Heme oxygenase-1: function, regulation, and implication of a novel stress-inducible protein in oxidant-induced lung injury. American Journal of Respiratory Cell and Molecular Biology 15 9-19.

Cymeryng CB, Dada LA \& Podesta EJ 1998 Effect of nitric oxide on rat adrenal zona fasciculata steroidogenesis. Journal of Endocrinology $\mathbf{1 5 8}$ 197-203.

Cymeryng CB, Dada LA, Colonna C, Mendez CF \& Podesta EJ 1999 Effects of L-arginine in rat adrenal cells: involvement of nitric oxide synthase. Endocrinology 140 2962-2967.

Cymeryng CB, Lotito SP, Colonna C, Cornejo MF \& Podesta EJ 2000 Induction of nitric oxide synthase activity in adrenal cells. Endocrine Research 26 589-595.

Cymeryng CB, Lotito SP, Colonna C, Finkielstein C, Pomeraniec Y, Grion N, Gadda L, Maloberti P \& Podesta EJ 2002 Expression of nitric oxide synthases in rat adrenal zona fasciculata cells. Endocrinology 143 1235-1242.

Datta PK \& Lianos EA 1999 Nitric oxide induces heme oxygenase-1 gene expression in mesangial cells. Kidney International 55 1734-1739.

Datta PK, Gross EJ \& Lianos EA 2002 Interactions between inducible nitric oxide synthase and heme oxygenase- 1 in glomerulonephritis. Kidney International 61 847-850.

Enriquez de Salamanca A \& Garcia R 2005 Response of rat fasciculatareticularis cells in primary culture to bacterial lipopolysaccharide. Microbes and Infection 7 1077-1086.

Foresti R \& Motterlini R 1999 The heme oxygenase pathway and its interaction with nitric oxide in the control of cellular homeostasis. Free Radical Research 31 459-475.

Foresti R, Clark JE, Green CJ \& Motterlini R 1997 Thiol compounds interact with nitric oxide in regulating heme oxygenase- 1 induction in endothelial cells. Involvement of superoxide and peroxynitrite anions. Journal of Biological Chemistry 272 18411-18417.

Harada S, Imaki T, Chikada N, Naruse M \& Demura H 1999 Distinct distribution and time-course changes in neuronal nitric oxide synthase and inducible NOS in the paraventricular nucleus following lipopolysaccharide injection. Brain Research 821 322-332.
Immenschuh S \& Ramadori G 2000 Gene regulation of heme oxygenase-1 as a therapeutic target. Biochemical Pharmacology 60 1121-1128.

Immenschuh S, Stritzke J, Iwahara S \& Ramadori G 1999 Up-regulation of heme-binding protein 23 (HBP23) gene expression by lipopolysaccharide is mediated via a nitric oxide-dependent signaling pathway in rat Kupffer cells. Hepatology 30 118-127.

Jacobs RA, Satta MA, Dahia PL, Chew SL \& Grossman AB 1997 Induction of nitric oxide synthase and interleukin-1beta, but not heme oxygenase, messenger RNA in rat brain following peripheral administration of endotoxin. Brain Research. Molecular Brain Research 49 238-246.

Kitamura Y, Furukawa M, Matsuoka Y, Tooyama I, Kimura H, Nomura Y \& Taniguchi T 1998 In vitro and in vivo induction of heme oxygenase-1 in rat glial cells: possible involvement of nitric oxide production from inducible nitric oxide synthase. Glia 22 138-148.

Kostoglou-Athanassiou I, Costa A, Navarra P, Nappi G, Forsling ML \& Grossman AB 1998 Endotoxin stimulates an endogenous pathway regulating corticotropin-releasing hormone and vasopressin release involving the generation of nitric oxide and carbon monoxide. Journal of Neuroimmunology 86 104-109.

Ma XC, Chen LT, Oliver J, Horvath E \& Phelps CP 2000 Cytokine and adrenal axis responses to endotoxin. Brain Research 861 135-142.

Maines MD 1997 The heme oxygenase system: a regulator of second messenger gases. Annual Review of Pharmacology and Toxicology 37 517-554.

Maines MD, Trakshel GM \& Kutty RK 1986 Characterization of two constitutive forms of rat liver microsomal heme oxygenase. Only one molecular species of the enzyme is inducible. Journal of Biological Chemistry 261 411-419.

Mancuso C, Ragazzoni E, Tringali G, Liberale I, Preziosi P, Grossman A \& Navarra P 1999 Inhibition of heme oxygenase in the central nervous system potentiates endotoxin-induced vasopressin release in the rat. Journal of Neuroimmunology 99 189-194.

McCoubrey WK Jr, Huang TJ \& Maines MD 1997 Isolation and characterization of a cDNA from the rat brain that encodes hemoprotein heme oxygenase-3. European Journal of Biochemistry 247 725-732.

Michel T \& Feron O 1997 Nitric oxide synthases: which, where, how, and why? Journal of Clinical Investigation 100 2146-2152.

Moncada S, Palmer RM \& Higgs EA 1991 Nitric oxide: physiology, pathophysiology, and pharmacology. Pharmacological Reviews 43 109-142.

Morgan ET, Ullrich V, Daiber A, Schmidt P, Takaya N, Shoun H, McGiff JC, Oyekan A, Hanke CJ, Campbell WB et al. 2001 Cytochromes P450 and flavin monooxygenases-targets and sources of nitric oxide. Drug Metabolism and Disposition 29 1366-1376.

Otterbein LE \& Choi AM 2000 Heme oxygenase: colors of defense against cellular stress. American Journal of Physiology. Lung Cellular and Molecular Physiology 279 L1029-L1037.

Palmer RM, Ashton DS \& Moncada S 1988 Vascular endothelial cells synthesize nitric oxide from L-arginine. Nature 333 664-666.

Pomeraniec Y, Grion N, Gadda L, Pannunzio V, Podesta EJ \& Cymeryng CB 2004 Adrenocorticotropin induces heme oxygenase-1 expression in adrenal cells. Journal of Endocrinology 180 113-124.

Rizzardini M, Terao M, Falciani F \& Cantoni L 1993 Cytokine induction of haem oxygenase mRNA in mouse liver. Interleukin 1 transcriptionally activates the haem oxygenase gene. Biochemical Journal 290 343-347.

Ryter SW \& Tyrrell RM 2000 The heme synthesis and degradation pathways: role in oxidant sensitivity. Heme oxygenase has both pro- and antioxidant properties. Free Radical Biology and Medicine 28 289-309.

Ryter SW, Otterbein LE, Morse D \& Choi AM 2002 Heme oxygenase/carbon monoxide signaling pathways: regulation and functional significance. Molecular and Cellular Biochemistry 234-235 249-263.

Satta MA, Jacobs RA, Kaltsas GA \& Grossman AB 1998 Endotoxin induces interleukin-1beta and nitric oxide synthase mRNA in rat hypothalamus and pituitary. Neuroendocrinology 67 109-116.

Srisook K \& Cha YN 2004 Biphasic induction of heme oxygenase-1 expression in macrophages stimulated with lipopolysaccharide. Biochemical Pharmacology 68 1709-1720. 
Takahashi K, Hara E, Suzuki H, Sasano H \& Shibahara S 1996 Expression of heme oxygenase isozyme mRNAs in the human brain and induction of heme oxygenase-1 by nitric oxide donors. Journal of Neurochemistry 67 482-489.

Tenhunen R, Marver HS \& Schmid R 1969 Microsomal heme oxygenase. Characterization of the enzyme. Journal of Biological Chemistry 244 6388-6394.

Turcanu V, Dhouib M \& Poindron P 1998 Nitric oxide synthase inhibition by haem oxygenase decreases macrophage nitric-oxide-dependent cytotoxicity: a negative feedback mechanism for the regulation of nitric oxide production. Research in Immunology 149 741-744.

Uribe RM, Lee S \& Rivier C 1999 Endotoxin stimulates nitric oxide production in the paraventricular nucleus of the hypothalamus through nitric oxide synthase I: correlation with hypothalamic-pituitary-adrenal axis activation. Endocrinology 140 5971-5981.
Wang WW, Smith DL \& Zucker SD 2004 Bilirubin inhibits iNOS expression and NO production in response to endotoxin in rats. Hepatology 40 424-433.

White KA \& Marletta MA 1992 Nitric oxide synthase is a cytochrome P-450 type hemoprotein. Biochemistry 31 6627-6631.

Yee EL, Pitt BR, Billiar TR \& Kim YM 1996 Effect of nitric oxide on heme metabolism in pulmonary artery endothelial cells. American Journal of Physiology 271 L512-L518.

\section{Received in final form 13 March 2007 \\ Accepted 4 April 2007 \\ Made available online as an Accepted Preprint \\ 11 April 2007}

